\title{
Paulo Freire, alfabetização e inclusão escolar: o direito à educação a partir da formação crítico e reflexiva
}

\section{Paulo Freire, literacy, and school inclusion: the right to education from critical and reflective training \\ Paulo Freire, alfabetización e inclusión escolar: el derecho a la educación desde la formación crítica y reflexiva}

\author{
ELAINE CONSTANT \\ http://orcid.org/0000-0003-2622-8890 \\ Universidade Federal do Rio de Janeiro \\ Programa de Pós-graduação de Políticas Públicas e Direitos Humanos \\ Rio de Janeiro, RJ, Brasil \\ SANDRA CORDEIRO DE MELO \\ http://orcid.org/0000-0002-8437-1671 \\ Universidade Federal do Rio de Janeiro \\ Programa de Pós-Graduação em Educação \\ Rio de Janeiro, RJ, Brasil \\ DAIANE FRANÇA \\ http://orcid.org/0000-0002-4284-3482 \\ Fundação de Apoio à Escola Técnica - Faetec \\ Rio de Janeiro, RJ, Brasil
}

\begin{abstract}
Resumo: Este artigo apresenta uma revisão da literatura sobre a relação entre alfabetização, inclusão e a perspectiva de Paulo Freire. Discute o aumento do índice de analfabetismo no Brasil e analisa as contribuições freireanas no contexto da formação de professores. O texto se desenvolve por dois eixos analíticos: alfabetização e letramento como processos de inclusão social e a construção política dos princípios de Educação para Todos. Aponta para além das lutas no campo educacional contra o analfabetismo absoluto e funcional, os novos riscos: o analfabetismo virtual e os refugiados digitais.
\end{abstract}

Palavras-chave: alfabetização; direito à educação; inclusão social.

Abstract: This article presents a literature review on the relationship between literacy, inclusion, and Paulo Freire's perspective. It discusses the increase in the illiteracy rate in Brazil and analyzes Freire's contributions in the context of teacher education matter. The text develops along two analytical axes: initial reading instruction and literacy as processes of social inclusion, and the political construction of the principles of Education for All. The study points beyond the struggles in the educational field against absolute and functional illiteracy, the new risks: virtual illiteracy and digital refugees.

Keywords: literacy; right to education; social inclusion. 
Resumen: Este articulo presenta una revisión de la literatura sobre la relación entre alfabetización, inclusión y la perspectiva de Paulo Freire. Discute el aumento de la tasa de analfabetismo en Brasil y analiza las contribuciones de Freire al contexto de la formación docente. El texto se desarrolla en dos ejes analíticos: la alfabetización y la literacidad como procesos de inclusión social y la construcción política de los principios de Educación para Todos. Señala más allá de las luchas en el campo educativo contra el analfabetismo absoluto y funcional, los nuevos riesgos: el analfabetismo virtual y los refugiados digitales.

Palabras-clave: Alfabetización; Derecho a la educación; Inclusión social.

\section{INTRODUÇÃO}

Desde a década de 1980, a escola vem mostrando a necessidade de se transformar, o que no contexto atual de uma pandemia se torna urgente. Somado a isto, os índices de analfabetismo das últimas décadas que vinham diminuindo, com a necessidade de isolamento social, o ensino remoto e híbrido, estes têm aumentado vertiginosamente.

Este artigo tem por objetivo somar esforços nas lutas por uma transformação do campo educacional que busca torná-la para todos, sem exceção. Entendemos que este caminho passa pela análise da situação do analfabetismo no Brasil, do movimento de uma educação para todos ${ }^{1}$, da necessidade de aprimorar a formação de professores e pelo resgate dos pressupostos da educação crítica e reflexiva de Paulo Freire. Para tanto, realizamos uma revisão da literatura recente no banco de dados Google Scholar a partir de três descritores: Paulo Freire, alfabetização e inclusão. Esta primeira busca gerou 5.800 resultados. Optamos por inserir novos descritores para tornar mais assertiva a nossa pesquisa: Paulo Freire, Alfabetização, Inclusão Escolar, Deficiência, Educação e Políticas Educacionais, nesta busca chegamos a 475 resultados. Em uma terceira filtragem uma análise foi feita priorizado os textos que continham as palavras: Paulo Freire, Alfabetização e Inclusão Escolar e eliminamos os artigos sobre Alfabetização Científica e Alfabetização Matemática, gerando 49 resultados. Realizamos a leitura dos documentos e percebemos que, destes, apenas 18 estavam alinhados à nossa discussão.

Os artigos foram analisados sob o método da Análise de Conteúdo com o auxílio do software ATLAS. Ti versão 9.0 (2020). Este software contribui para o tratamento dos dados qualitativos, além de auxiliar na sua organização e categorização. A análise dos artigos selecionados, identificou 4 temáticas que

\footnotetext{
1

As autoras do artigo defendem que a educação se torne uma realidade para "todos", mas sem o apagamento de professores e estudantes como indivíduos sócio-históricos, como que haja a valorização de um projeto de educação pública universal e democrática.
}

1394 - Rev. Bras. Polít. Adm. Educ. - v. 37, n. 3, p. 1393 - 1412, set./dez. 2021 
serão discutidas ao longo deste artigo: Letramento e Alfabetização, Educação para Todos, Inclusão e Direitos à Educação, Formação de Professor e Educação Crítico e Reflexiva.

O presente estudo se desenvolve a partir de dois eixos analíticos: a discussão sobre alfabetização e letramento como processos de inclusão social, e a construção política dos princípios de uma Educação para todos, do conceito de Inclusão em Educação como bases para o direito fundamental à educação. Os artigos analisados chamam à constituição do "aluno-cidadão" e a importância da "pedagogia crítica", pois, ambos possuem em comum o compromisso éticopolítico com a transformação da sociedade e da prática social. Este estudo defende que a perspectiva Crítica e Reflexiva é um importante caminho para favorecer alterações na alfabetização, tanto de crianças, como da Educação de Jovens e Adultos. Neste sentido, articulamos alguns pontos: a transformação precisa alcançar a todos, sem exceção, o que nos leva a pensar nos processos de inclusão em educação e nas lutas pelas garantias por direitos à educação. Para tanto, tornase fundamental resgatar os pressupostos da educação crítica e reflexiva de Paulo Freire, temas que serão discutidos a seguir.

\section{ALFABETIZAÇÃO VERSUS ANALFABETISMO FUNCIONAL: O LETRAMENTO COMO PROJETO DE INCLUSÃO SOCIAL}

A realidade educacional brasileira, conforme dados estatísticos oriundos da Avaliação Nacional do Rendimento Escolar - ANRESC (Prova Brasil) ${ }^{2}$ e do Programa Internacional de Avaliação de alunos (PISA), evidencia a necessidade de rever as práticas de ensino de Português, em especial, para a alfabetização escolar ${ }^{3}$ e da matemática nos anos iniciais do ensino fundamental. Há a preocupação com práticas alfabetizadoras que sejam mais exitosas para assegurar a permanência dos estudantes nas diferentes modalidades da escolarização.

Atualmente, o Brasil possui cerca de 16 milhões de analfabetos, sendo as cidades de São Paulo e Rio de Janeiro os municípios que encabeçam a lista ${ }^{4}$. O quantitativo, em todo o país, vem preocupando os implementadores de políticas

2 Esta avaliação era realizada com todos os alunos matriculados no $2^{\circ}$ ano de escolarização pública pelo INEP para compreender o que fora agregado, ao longo do ano letivo, na aprendizagem dos alunos. (BRASIL, 2008). A Avaliação Nacional do Rendimento Escolar (ANRESC) e a Avaliação Nacional da Educação Básica (ANEB), juntamente compõe Sistema Nacional de Avaliação da Educação Básica (SAEB) do Brasil..

3 Tomamos como referência uma expressão utilizada por Maria do Rosário Mortatti (2010). A alfabetização escolar é aquela que acontece em lugar apropriado e preparado, para isto: o espaço escolar, caracterizando-se dever do Estado e direito constitucional assegurado às crianças.

$4 \quad$ Na primeira cidade há possivelmente 383 mil, enquanto na segunda 199 mil. Consultar: http://www. publicacoes.inep.gov.br/arquivos. Em 31/10/2020. 
educativas, embora tenha ocorrido à ampliação do atendimento escolar nos sistemas públicos de ensino durante o século XX, ainda se observa "como dado negativo, [que] havia em 2000 um número maior de analfabetos do que aquele existente em 1960 e quase duas vezes e meia o que havia no início do século 20" (Brasil, 2011) ${ }^{5}$. Esses dados mostram as inquietações atuais com diferentes instâncias públicas e instituições sociais para lidar com a questão do analfabetismo e suas diferentes perspectivas de entendimentos, pois, na medida em que se amplia a universalização e o acesso ao ensino público, observa-se mais dificuldades para alguns estudantes permanecerem em um determinado sistema educativo.

Neste sentido, as contribuições de Paulo Freire para o campo da alfabetização, independente da faixa etária, crianças ou jovens e adultos, se tornam prementes, porque a preocupação com o êxito do ensino da Língua Portuguesa já vem acompanhando a história da Educação brasileira desde longa data. Sendo assim, algumas reflexões podem ser suscitadas na atualidade, observando os sentidos para "ensinar a ler e escrever" ou "alfabetizar", em especial, a partir de determinados períodos históricos e sociais, uma vez que em cada contexto há preocupações distintas e objetivos apropriados diante de um cenário políticoeconômico.

Assim, ainda que breve, apresentaremos alguns episódios históricos que podem elucidar a complexidade do campo da alfabetização no Brasil. Conforme Mortatti (2004) , a preocupação com a instrução elementar se apresentou no Brasil durante o século XVIII, contudo, somente no final do Império, a partir da inquietação com novos fatos e ideias relacionadas com a Proclamação da República, houve certa visibilidade sobre a condição de analfabeto e sua correspondência ao "analfabetismo". Esta associação foi resultante de um problema eminentemente político, em especial, com a proibição do voto do analfabeto entre os anos de 1881 e 1882 e a necessidade da instalação do modelo republicano de escola pública em 1889.

Este processo se ampliou, conforme Mortatti (2004), nas décadas de 1910 e 1920 com as altas taxas de reprovação no curso primário. Foi neste período que Sampaio Dória elaborou uma carta aberta, intitulada "Contra o analphabetismo". Neste documento apresentaram-se as bases de um plano para a extinção do analfabetismo, pois era considerado um "monstro canceroso" e o "maior mal do Brasil" (p.60). Juntamente com as crescentes taxas de analfabetismo, houve a consolidação da expansão do "aparelho escolar" e da disseminação da instrução pública elementar. Este período, marcado pelos problemas econômicos da Primeira Guerra Mundial e problemas sociais e culturais gerados a partir do 
processo de urbanização, juntamente com a chegada de imigrantes no Brasil, favoreceu novos contornos e significados para o ensino da leitura e escrita no país. A partir desse contexto, se deu a difusão das palavras "analphabetismo", "analfabeto", "alphabetização", "alphabetizado" e a estreita relação da escola e com a finalidade de "ensino da leitura (e escrita)"

Contudo, durante boa parte do século XX, o aprendizado da Língua Portuguesa para crianças, considerando o binômio educação-alfabetização, se consolidou a partir de dois fins: 1. A valorização somente das práticas didáticopedagógicas e o modelo de educação; 2. A função socializadora da escola. Tais fins favoreceram a percepção de que a "alfabetização" se restringe às questões metodológicas, portanto voltadas para questões técnicas do ensino da leitura e escrita. Isso significa o silenciamento das abordagens políticas, como a relação entre linguagem e classe social, consequentemente, as desigualdades sociais e econômicas. Este fato chama a atenção, pois os estudos sobre a alfabetização foram adiados e demoraram para ser enfrentados por estudos e pesquisas acadêmicas, porque as abordagens tradicionais insistiam que o ensino da Língua Portuguesa se resumia na simples decodificação de letras, sílabas ou frases. Assim, o caráter técnico facilitava a produção de materiais didáticos padronizados e sua ampla distribuição.

Ainda no decorrer do século XX, constata-se que preocupações com a difusão do ensino da Língua e o pronto atendimento para jovens e adultos analfabetos marcaram o percurso sobre os debates da alfabetização em massa no Brasil. Isso incluía o atendimento rápido para esses grupos, pois era significativo o percentual de indivíduos, sem nenhuma escolarização, distribuído pelas capitais e cidades do interior. Daí resultaram, até a década de 1990, campanhas, movimentos, planos e programas ${ }^{7}$ em que a preocupação com o analfabetismo estava relacionada com os indivíduos que não estavam mais no percurso regular na escola.

Assim, o foco no analfabetismo, em especial, sobre a educação de jovens e adultos se manteve por um longo tempo. Significa que não se considerava esse tipo de situação para os alunos que estavam no fluxo considerado "normal" ou de acordo com a faixa etária. Os exitosos podiam permanecer durante anos na escola, sendo bem-sucedidos e mantidos no sistema escolar, uma situação muito distinta da atualidade, em especial, frente a uma pandemia. Cabe ressaltar que o

\footnotetext{
6 Em razão desta realidade, destaca-se que a leitura se tornou o eixo para "alphabetização", considerando as dificuldades para se obter materiais apropriados para a escrita.

7 Citamos as seguintes propostas: Campanha de Educação de Adolescentes e Adultos; Campanha Nacional de Educação Rural (CNER); Campanha Nacional de Erradicação do Analfabetismo (CNEA), Programa Brasil Alfabetizado, Fundação Educar, Programa Alfabetização Solidária (PAS).
} 
ensino público, particularmente até 1988, era considerado eficiente para os grupos sociais que frequentavam o espaço escolar e conseguiam lidar com a meritocracia. Após a atual Constituição Federal e a redemocratização do Brasil, este cenário muda, porque a obrigatoriedade escolar e as punições para pais e responsáveis, por ausência dos estudantes nas salas de aula e com o trabalho infantil, favoreceram a presença massiva de crianças, jovens e alunos na educação pública.

Hoje, o debate sobre o analfabetismo, se move para toda a escola básica, em especial, para os anos iniciais do ensino fundamental. Contudo, percebe-se que domínio do sistema de leitura e escrita vem exigindo níveis mais complexos para a continuidade na trajetória escolar. Novas demandas se apresentam para que os estudantes consigam lidar com diferentes níveis de interpretações, a partir de distintos gêneros discursivos da escrita e prosseguir nos níveis de escolarização. Dessa forma, há mudanças significativas sobre a alfabetização dos alunos do ensino público, portanto, sobre as classes sociais mais pobres e filhos de trabalhadores precarizados.

Diante dessas novas exigências para as complexas práticas do ler e do escrever resultantes da aprendizagem do sistema de escrita, ainda há muito para se pesquisar sobre o analfabetismo. Contudo, importa lembrar que, justamente a partir da Constituição de 1988, inicia-se, no Brasil, o desenvolvimento de estudos e pesquisas acadêmicas sobre educação, alfabetização e cidadania. Houve uma mobilização para o envolvimento e a participação de professores universitários dos Centros de pesquisas e de cursos de pós-graduação e na organização de serviços de extensão universitária, por meio de programas de formação continuada de professores, objetivando a incorporação da pesquisa científica e de novos conhecimentos sobre alfabetização. (MORTATTI, 2004)

Cabe destacar que, com a redemocratização do Brasil, houve o retorno do diálogo sobre o direito à educação, tornando-se legal, em 1988, pela Constituição Federal. Isso foi fundamental, pois se vislumbrou, a partir do pensamento freireano, a necessidade de práticas educativas que dialogassem com os vários saberes e circundassem o universo de possibilidades de compreensão do mundo. Constituía-se assim, a educação para os direitos, a defesa da escola pública e da formação continuada de professores. Significava a luta pela melhoria dos padrões de ensino e essa era fundamental em um projeto político-pedagógico que incluía estudos e pesquisas sobre a alfabetização e suas práticas.

Já a partir de 1990, deu-se um crescente interesse por estudos e pesquisas científicas sobre alfabetização escolar. Neste período, considerado como a "década da educação", houve a publicação da Lei de Diretrizes e Bases da Educação Nacional No 9.394/96 (LDB), bem como a defesa da escola pública em um modelo democrático para todos. Entretanto, a educação brasileira estava 
alinhada ao projeto neoliberal, a partir de fundamentos e intencionalidades para uma "nova" ordem política, econômica e social. Neste alinhamento, duas agências internacionais se destacaram: a Organização das Nações Unidas para a Educação, a Ciência e a Cultura (Unesco) e a Organização para a Cooperação e Desenvolvimento Econômico (OCDE). Essas são organizações multilaterais que fomentam ainda a competitividade na educação por meio de relatórios, dados, índices e termos de cooperação com os governos, prevendo metas e diretrizes a serem alcançadas, sobretudo, no campo da alfabetização. Estas agências proporcionaram mudanças significativas, pois exigiram alterações curriculares e didático-pedagógicas nos países da América Latina, logo incidiram, e ainda até hoje, no processo de formação de professores.

De acordo com Moura et.al. (2019), a função de organismos multilaterais na propagação de diagnósticos e diretrizes influenciam as políticas educacionais na América Latina e no Brasil. Tais grupos foram estabelecendo "movimentos reformadores", mas esses necessitam ser questionados, pois seus projetos objetivam mudar a realidade educacional das piores escolas públicas das cidades. Isso pode ser constatado na financeirização e o caráter filantrópico de parcerias que se beneficiam de profissionais da educação frente a docentes tradicionais. Entretanto, os autores alertam para o pouco rigor acadêmico destas parcerias e de suas propostas, pois essas não respondem às demandas de escolas públicas dos países, sendo, portanto, mais uma articulação com valor agregado de trocas. O que se apresenta é um discurso de que professores brilhantes e obstinados dispõe de poder, por seus atributos individuais para enfrentar as desigualdades educacionais. Já os professores tradicionais não obteriam esse "ganho", pois não se esforçaram ou são suficientemente talentosos.

Já o estudo de Martínez e Seoane (2020) mostra que o neoliberalismo é um projeto transnacional e de uma classe político-econômica designado para reconstruir o nexo do mercado, do Estado e da cidadania. Assim, os grupos de empresários e executivos de bancos e empresas, assim como políticos e administradores, atuam por dentro do Estado e em prol dos interesses de organizações internacionais como Organização para Cooperação e Desenvolvimento Econômico (OCDE). Esse último condiciona a linha de financiamento a aceitação de suas recomendações para as políticas educacionais que deverão ser promovidas pelos governos dos países, em especial, da América Latina.

Tais orientações definem o comportamento dos professores, indicando as capacidades que devem demonstrar em um sistema institucional para melhorar seu desempenho docente e se manter no trabalho. Justamente este tipo de governabilidade faz parte de reestruturação das relações da atuação em um 
sistema educacional. Isso altera significativamente as conquistas profissionais e trabalhistas dos professores, porque as políticas neoliberais na educação não são simplesmente mudanças na educação pública, mas envolvem reformas referentes à identidade docente, colocando em jogo as representações que os professores têm de si e a forma como estabelecem relações com outros colegas. Isso pode ser percebido nas estratégias para colocar o professor como principal responsável por uma "crise educacional" expressa através dos "maus resultados" e, desse modo, justifica-se a urgência de uma reconfiguração do setor público para melhoria da escolarização da educação pública.

Conforme Infante (1999), a baixa qualidade da escolarização desemboca em um precário manejo do código escrito, cujo domínio é indispensável para se desenvolver em uma vida diária, seja pessoal ou profissional. Da mesma forma, a complexidade da dicotomia analfabetos versus alfabetizados exige avançar no reconhecimento de que alfabetização é um contínuo, começando na fase inicial na infância e de desenvolvendo por toda vida. Isso se configurará na concepção de "analfabetismo funcional", porque é difícil de dimensionar e caracterizar os possíveis "analfabetos funcionais", não somente em termos comparativos entre países, pois esses apresentam diferentes níveis de desenvolvimento tecnológico, mas nos distintos graus de modernização em geral, não somente na América Latina, mas também nos grupos de um mesmo país. Neste sentido, precisa-se considerar as restrições para se avaliar os níveis de alfabetização de um determinado país. Os autores alertam sobre os riscos para medir certas habilidades com a leitura e escrita, porque não se pode desconsiderar as complexas redes culturais que ajudam as pessoas a desenvolverem o pensamento e a comunicação. Portanto, é fundamental resgatar, por meio das abordagens e dimensões qualitativas e que ainda se mostram marginalizadas em vários estudos sobre a alfabetização.

Considerando o contexto brasileiro, a partir de 2000, as decisões políticas e pedagógicas do Ministério da Educação (MEC), encaminharam a questão da diminuição do analfabetismo dos alunos nas turmas iniciais do ensino fundamental das classes mais pobres, pois o país obteve índices baixos no PISA. Este instrumento detectou que $50 \%$ dos alunos que participaram da avaliação foram enquadrados como analfabetos funcionais.

Para Paiva (1987), o conceito de analfabetismo funcional se desenvolveu no cenário educacional a partir da década de 1960. Compreendia, inicialmente, que a alfabetização era fundamental às atividades realizadas no dia a dia dos trabalhadores. Assim, o conceito surge como uma complementação ao conceito de analfabetismo absoluto e em decorrência do baixo desempenho de jovens e adultos na apropriação das técnicas de lecto-escritura e de cálculos importantes para a vida profissional, política ou social. Com as transformações 
sucessivas das tecnologias a partir de 1990, o conceito foi ressuscitado no ensino fundamental. Esta revalorização, como parte dos debates sobre a alfabetização, trouxe a importância da compreensão pelos alunos das escolas públicas de textos complexos, comunicar-se por escrito, conhecer as operações matemáticas diversas pelas novas possibilidades de comunicação.

Conforme pesquisas feitas em conjunto pelo Instituto Paulo Montenegro do IBOPE, com a ONG Ação Educativa, que deram destaque ao Indicador Nacional de Alfabetismo Funcional (INAF), o conceito é utilizado para designar o analfabetismo absoluto e aqueles que mostram uma alfabetização rudimentar. Atualmente, os progressos já são percebidos na transição do analfabetismo absoluto para a alfabetização rudimentar com um nível básico de habilidades de leitura e matemática. Por outro lado, ainda se mantém em torno de pouco mais de $25 \%$ da população dos que atingem um nível pleno de habilidades, em princípio, esperado ao completar os nove anos do ensino fundamental.

Tais indicadores favoreceram o aparecimento de medidas que incidiram diretamente sobre as práticas pedagógicas, em especial, dos professores alfabetizadores, tornando-os o centro do debate pedagógico. Para isto, as temáticas sobre alfabetização e letramento ganharam relevância e ainda mobilizam reflexões acerca de processos de formação continuada para professores nos sistemas públicos de ensino.

No Brasil, conforme Tayassu (2011), com inspiração em Paulo Freire, o legado sobre a 'arte de educar' (p.17) e construção de um objetivo comum devem ser associados às contribuições da ciência, para melhor ler e escrever. Assim, é importante que se faça a combinação dos dois processos - alfabetização e letramento -, pois não se considera apenas a aprendizagem da leitura, mas os usos da escrita e seu valor nas sociedades atuais. De acordo com a autora, os referidos processos são indispensáveis e indissociáveis à questão da inclusão social e cultural de um indivíduo ou de um grupo. Por fim, a autora advoga que "o acesso à alfabetização e ao letramento são condições fundamentais para um projeto de inclusão social” (p.19).

Nesse sentido, o desenvolvimento do processo de inclusão em educação é condição para garantia do direito para acesso e a permanência no sistema educacional. Defendemos que o letramento despontou como um recurso teóricometodológico, em período democrático, e esse objetivou formar indivíduos que precisavam se posicionar de modo crítico. Para isto, o estreitamento entre a prática pedagógica, a consciência política e o compromisso ético com o ser humano, pois a educação é uma forma de intervenção no mundo, conforme Paulo Freire. Neste sentido, uma "nova" perspectiva para o processo de leitura e escrita - o letramento -, trouxe urgências para a formação dos estudantes. Essas deveriam atentar que 
o "educar" não se atém somente ao ato de ler e escrever, mas forma cidadãos capazes de pensar criticamente, recorrendo às novas percepções sobre um determinado assunto. Assim, o letramento possui um caráter de desenvolvimento mais social, independente do domínio da leitura e escrita, como uma perspectiva de superação do analfabetismo funcional no país.

Até recentemente, a preocupação do MEC era com a baixa consistência entre a escolaridade e desempenho dos alunos. Este fato favoreceu a criação de algumas políticas públicas para lidar com a precária qualidade da alfabetização nos sistemas de ensino. Ainda que de forma tímida, vem se dando o debate sobre o "direito à alfabetização" e a construção de estratégias que possibilitem a diminuição de estatísticas negativas sobre as futuras gerações de estudantes. Este debate, no presente momento, volta-se mais às crianças que estão no sistema público de educação e não atingiram um determinado padrão, sendo consideradas malsucedidas, especialmente, porque não conseguem ler e escrever.

O insucesso dos alunos incomoda os professores brasileiros. Isso foi percebido nos artigos analisados neste trabalho, e se mostra com um aspecto de tensão para educação pública, porque ainda há grande quantitativo de reprovações e repetência na Educação Básica devido ao analfabetismo funcional. Este cenário também vem gerando mudanças nas práticas, bem como o aprofundamento sobre o conceito de letramento, tema recorrente entre os autores, mas algumas questões se destacam para esses pesquisadores: Por que algumas crianças, jovens e adultos ainda não se apropriaram da linguagem escrita? De que forma as perspectivas de classe, etnia, gênero e geração podem elucidar o "porquê" das desigualdades sociais e o analfabetismo no Brasil?

\section{EDUCAÇÃO PARA TODOS, INCLUSÃO E DIREITO À EDUCAÇÃO}

Para melhor compreensão sobre as desigualdades escolares, neste item abordaremos os seguintes tópicos levantados pelos estudos: direito à educação, os conceitos de inclusão em educação e os principais desafios apontados para que o processo de inclusão aconteça.

O momento atual de pandemia por causa do novo coronavírus e suas mazelas, vividas pelo mundo todo, afetou fortemente o campo da Educação quando, na implantação do ensino remoto e híbrido, para cumprir com os protocolos de isolamento social, desencadeou um quadro de desigualdades e exclusões que levantam a necessidade urgente de, como sociedade, reunir forças para continuar uma luta iniciada mais concretamente em 1990 com a Conferência de Jomtien que definiu metas globais e locais para uma Educação para Todos. No 
Brasil, o reflexo disso pode ser observado na emenda constitucional no 14/96 que deu nova redação aos incisos I e II do artigo 208 da Constituição Federal, definiu o ensino fundamental gratuito assegurando sua oferta para todos os que a ele não tiveram acesso na idade própria e determinou a progressiva universalização do ensino médio gratuito. A já citada lei de Diretrizes e bases da Educação Nacional (BRASIL, 1996) definiu 13 princípios da Educação, dentre eles a igualdade de condições de acesso e permanência na escola; a liberdade de aprender, ensinar, pesquisar e divulgar a cultura, o pensamento, a arte e o saber, o respeito à liberdade e apreço à tolerância, a consideração com a diversidade étnico-racial e a garantia do direito à educação e à aprendizagem ao longo da vida.

Em 2000, o Marco de Ação de Dakar reafirmou a visão da Declaração Mundial de Educação para Todos (EPT), assumiu que houve progressos, mas repudiou o fato de persistirem pessoas analfabetas, sem acesso ao ensino primário. Levantou as discussões sobre a igualdade de gênero, que enfocam o fato de que as meninas permanecem em desvantagem em relação aos meninos no que tange ao acesso, permanência e conclusão dos sistemas de ensino, e alertou para o fato de que "a discriminação por gênero continue a permear os sistemas educacionais” (Marco de Ação de Dakar, 2000). Nesta Conferência, 164 países assumiram o compromisso de perseguir seis metas de Educação para Todos até 2015: o cuidado e a educação na primeira infância; educação primária universal; habilidades de jovens e adultos; alfabetização de adultos; paridade e igualdade de gênero; e qualidade da educação.

Na esteira desse movimento, em 2015, a Declaração de Incheon para a Educação 2030, estabeleceu uma nova visão para a educação dos próximos 15 anos (2015-2030) e definiu as metas do Objetivo de Desenvolvimento Sustentável (ODS) 4: "assegurar a educação inclusiva e equitativa de qualidade, e promover oportunidades de aprendizagem ao longo da vida para todos". Reafirmou a visão do Movimento Global de Educação para todos, reconheceu os esforços realizados, contudo constatou que "estamos longe de alcançar a educação para todos" (Declaração de Incheon para a Educação 2030, 2015). Este documento definiu ainda que o Movimento Global de Educação para Todos será o responsável por elaborar relatórios (Relatórios GEM) para monitorar o desenvolvimento dos ODS 4 e sobre educação nos outros ODS propostos, e inaugurou mundialmente uma perspectiva política de inclusão ampla que ultrapassa o universo das deficiências.

Esta mesma perspectiva vinha sendo defendida desde o início dos anos 2000 por Booth e Aincow no documento intitulado Index para Inclusão (2012, 2006, 2012, 2016). Os autores entendem os processos de inclusão em educação baseados em três dimensões: a das culturas associadas ao desenvolvimento de valores de inclusão, representações, justificativas de mundo, crenças arraigadas, 
modos de perceber a vida; a das políticas referentes à organização administrativa de uma instituição em apoio à inclusão, que perpassam os campos atitudinais e operacionais-administrativos que partem desde as leis, decretos e declarações, até as intenções que, explicitadas em diretrizes, têm por objetivo orientar as práticas cotidianas; e a das práticas que se referem ao planejamento e execução curriculares, a tudo o que somos e fazemos, seja concreta ou abstratamente. A ideia proposta é a de que a comunidade escolar reflita e desenvolva culturas, políticas e práticas mais inclusivas.

Os estudos e pesquisas baseados no Index foram desenvolvidos desde então em diversos países do mundo e, no Brasil, Santos (2013) que representa o documento no país, vêm elaborando uma nova perspectiva denominada Omnilética, que parte da tridimensionalidade do Index e a amplia, entendendo que as relações entre as dimensões das culturas, políticas e práticas são dialéticas e complexas. A autora propõe uma multilente, uma maneira de compreender a dialeticidade e complexidade com que as dimensões culturais, políticas e práticas se apresentam e se entrelaçam.

Em 2020, o Relatório de Monitoramento Global da Educação, intitulado Inclusão e Educação, todos sem exceção (2020) reafirmou a ideia de inclusão ampla, chamou a atenção para o fato de que os "sistemas educacionais são inclusivos somente na medida em que quem os elabora os torna mais inclusivos" (RMGE, 2020), sinalizando que os governos têm a responsabilidade de desenvolver políticas públicas que favoreçam a participação e a aprendizagem de todos, e alertou para o fato de que:

as oportunidades educacionais continuam a ser distribuídas de forma desigual. Muitos estudantes ainda encontram grandes barreiras a uma educação de qualidade. Mesmo antes da atual pandemia, um em cada cinco adolescentes, jovens e crianças, estava totalmente excluído da educação. Além disso, a existência de estigmas, estereótipos e discriminação significa que outros milhões são excluídos nas próprias salas de aula (RMGE, 2020).

Para fins deste artigo, importa-nos discutir dentre os 17 ODS, o de número 4 - Educação de qualidade, e neste, os objetivos

4c: até 2030, substancialmente aumentar o contingente de professores qualificados, inclusive por meio da cooperação internacional para a formação de professores, nos países em desenvolvimento, especialmente os países de menor desenvolvimento relativo e pequenos Estados insulares em desenvolvimento e; 4.6: até 2030, garantir que todos os jovens e uma substancial proporção de adultos, homens, mulheres, estejam alfabetizados e tenham adquirido o conhecimento básico de matemática. 
Neste sentido, formar professores para o contexto de inclusão, de transformação e garantir a alfabetização de todos, sem exceção, se torna uma tarefa urgente. Pensando nisso, dentre os 18 artigos analisados, o de Silva, Almeida Junior e Dias, (2020) intitulado Como preparar um professor para "ser" inclusivo: reflexões sobre a formação docente, chama a atenção para o fato de que, em que pese esta ser uma publicação internacional, seus autores serem professores, servidores públicos que exercem suas funções em instituições estaduais e federais de educação no Brasil, afirmam que 3 das principais normativas nacionais para a educação nacional não trazem em si o termo educação inclusiva, e por isso colocam em dúvida a legitimidade destes documentos como orientadores de processos formativos para a inclusão.

Esta perspectiva nos preocupa pois o Estado, diferente do cidadão, só pode fazer aquilo que está previsto em lei, e impedido naquilo que a norma vigente não prevê. Se o entendimento for de que as normativas que regulam a formação de professores para a inclusão estão sob suspeita, o Estado deixa de atuar. Caso este entendimento seja apenas pontual, a preocupação persiste, pois o despreparo de alguns pode acarretar a perda de grandes conquistas.

O estudo aborda a ação formativa docente no que tange os processos de inclusão em educação, utiliza da pesquisa documental de artigos científicos e especificamente das Diretrizes Curriculares Nacionais para o Curso de Graduação em Pedagogia (Resolução CNE/CP No 1, de 2006). A análise deste documento foi realizada por meio da técnica de leitura scanning, para encontrar as palavras/termos inclusão, educação inclusiva, inclusiva, acessível, acessibilidade, necessidades, adequação curricular. Esta prática consiste na "procura de certo tópico da obra, utilizando o índice ou sumário, ou a leitura de algumas linhas, parágrafos, visando encontrar frases ou palavras-chave" (MARCONI e LAKATOS, 2003). Os autores criticam a ausência do termo "Educação Inclusiva" no referido documento e atribuem o fato

à sua falta também na LDB - Lei de Diretrizes e Bases da Educação de 1996, nos PCN'S - Parâmetros Curriculares da Inclusão de 2003 e também na LBI - Lei Brasileira de Inclusão de pessoas com necessidades que é mais recente de 2015, leis essas que podem ter norteado a fundamentação teórica dessa resolução. O certo é que essa não aparece nos documentos que fundamentam oficialmente as diretrizes da inclusão em nosso país.

Acontece que nas normativas internacionais, o termo inclusão surge efetivamente na Declaração de Incheon (2015), contudo isto não quer dizer que este conceito não tenha tido o seu processo de construção desde a Declaração 
Mundial de Educação para Todos (1990), e antes disso na Declaração Universal dos Direitos Humanos (1948). No Brasil, a LDB (Lei 9394/96) trouxe a ideia de inclusão em seu texto quando no artigo $4^{\circ}$. Parágrafo $3^{\circ}$ afirma que:

O dever do Estado com educação escolar pública será efetivado mediante a garantia de: atendimento educacional especializado gratuito aos educandos com deficiência, transtornos globais do desenvolvimento e altas habilidades ou superdotação, transversal a todos os níveis, etapas e modalidades, preferencialmente na rede regular de ensino.

O "preferencialmente na rede regular de ensino" foi a porta de entrada, nas políticas nacionais, para todo um movimento em direção a processos mais inclusivos na educação, que influenciou uma série de normativas posteriores, inclusive a Lei Brasileira de Inclusão da Pessoa com Deficiência (2015). Esta, em seu texto, foca os processos de inclusão nas pessoas com deficiências "visando a sua inclusão social e cidadania", assume a presença de barreiras à sua participação social e afirma que a avaliação da deficiência deve ser biopsicossocial. Define o direito das pessoas com deficiência às residências inclusivas, escolas inclusivas e “adoção de práticas pedagógicas inclusivas pelos programas de formação inicial e conti nuada de professores".

Os autores citam o documento Saberes e Práticas da Inclusão: estratégias para a educação de alunos com necessidades educacionais especiais (BRASIL, SEE, 2003), contudo referem-se a ele como "PCN's - Parâmetros Curriculares da Inclusão". O documento de 2003, ao abordar a temática da educação para todos como conceito fundamental, considera que: "Ao pensar a implementação imediata do modelo de educação inclusiva nos sistemas educacionais de todo o país (nos estados e municípios), há que se contemplar alguns de seus pressupostos" (BRASIL, SEE, 2003, p. 23). O documento, além de citar o termo "educação inclusiva" questiona como deve ser a formação do professor para a inclusão.

Estes são documentos importantes para o cenário da Educação e expressam, cada um a seu tempo, a construção do conceito de inclusão. Ainda que o contexto de Educação para todos, e nele as questões relativas ao processo de alfabetização, dependa fortemente da formação de professores alinhada às políticas vigentes, os alunos com deficiência se apresentam como o público mais sensível aos problemas dessa formação. Kullmann e Lemons, em seu artigo intitulado: O papel do professor na libertação dos educandos, afirmam que "alinhar discurso e prática é um caminho sem volta" (2018). Nesse sentido, ampliar os esforços para formar professores em uma perspectiva mais inclusiva supõe considerar todos os alunos. Os autores continuam: "Comparamos esse 
primeiro movimento à expressão "nadar contra a maré". Muitos nos dirão que é difícil, que não vale a pena, que no final dá na mesma, que não recebem para isso, que o desgaste é grande. E é" (KULLMANN e LEMONS, 2018).

Por esses motivos defendemos que o investimento na formação docente é prioridade, pois favorece o crescimento de ações intencionais e estratégias de sucesso no processo de desenvolvimento dos alunos. No artigo de MELO e MASCARENHAS (no prelo), as autoras resgatam a pesquisa de Bialer (2015) sobre inclusão escolar a partir de autobiografias de alunos com Transtorno do Espectro Autista (TEA), e citam um relato de uma aluna sobre seu desejo de participar do contexto escolar:

Carly escreveu para a escola regular da qual queria fazer parte, explicando que rótulos estavam impedindo autistas de serem inseridos no sistema escolar e demandando o direito de ter as suas diferenças respeitadas. Salientava ter capacidade cognitiva para frequentar classes regulares e vontade de estudar e obter conhecimentos a despeito de suas dificuldades. Afirmava considerar que a função da escola é justamente ensinar jovens como ela, que têm a vontade e a capacidade de aprender conhecimentos novos.

MELO e MASCARENHAS (no prelo) apontam para o fato de que os esforços da escola têm alcançado resultados positivos, com experiências de escolarização promissoras. As autoras afirmam que o fato de a comunidade escolar ser cada vez mais plural desencadeia o que Zanette e Toniazzo (2018) entendem como propulsor da aprendizagem, na medida que o professor assume o papel de problematizador e mediador da aprendizagem, portanto, as contribuições freirianas se alinham plenamente ao projeto de inclusão em Educação. Neste contexto o diálogo admite fundamental importância pois "é, por meio dele "que o docente oferece condições, nos espaços escolares, para o aluno aprender os saberes historicamente construídos pela humanidade, desafiando-o a construir novos saberes" (ZANETTE e TONIAZZO, 2018).

\section{ALGUMAS POSSÍVEIS CONCLUSÕES}

Este estudo, a partir da necessidade de compreender os rumos da alfabetização frente a uma pandemia e os ataques frequentes e contundentes advindos do atual governo sobre a teoria freiriana, acabou por suscitar o resgate da "pedagogia crítica reflexiva". Isso resultou na revisão da literatura recente sobre os textos produzidos a partir das contribuições do autor para o campo da alfabetização, relacionando com o cenário de educação para todos. O presente texto oportunizou o debate sobre o direito à educação e à inclusão social e escolar, que se traduziu no material analisado neste estudo, pois para os distintos 
pesquisadores, os "direitos de formação" se tornaram um conceito central de apoio à organização dos cursos para professores alfabetizadores. Assim, a sonhada melhoria da qualidade da educação não será uma realidade, se o processo formativo não aprofundar outro conceito igualmente importante para o direito à educação: os debates sobre os processos de inclusão em uma efetiva política de formação continuada para professores.

Ressaltamos que, diante de um cenário de pandemia e da necessidade de isolamento social, tornam-se urgentes estudos sobre as questões econômicas, sociais e culturais que irão se impor no campo educacional, especialmente, no didático-pedagógico. Isso pressupõe indagações sobre as dificuldades vividas por professores, estudantes e seus familiares. Significa então, análises que superem os protocolos não somente da proteção da vida imediata, mas por toda existência, pois o analfabetismo "mata" tanto quanto o "vírus" e esse fato não pode ser banalizado. Há que se definir um projeto político-pedagógico para o Brasil que inclua os analfabetos funcionais, e também o analfabeto virtual, pois, corre-se o risco real de computarmos no próximo censo a categoria dos "refugiados digitais", derivados das desigualdades advindas do ensino remoto e híbrido.

\section{REFERÊNCIAS}

BIALER, Marina. A inclusão escolar nas autobiografias de autistas. Revista Quadrimestral da Associação Brasileira de Psicologia Escolar e Educacional, SP. Volume 19, Número 3, Setembro/Dezembro de 2015: 485-492.

BRASIL. Constituição (1988) Constituição: República Federativa do Brasil. Brasília, DF: Senado Federal, 1988.

BRASIL/MEC. Lei $\mathbf{n}^{\mathbf{0}} \mathbf{9 . 3 9 4}$, de 20 de dezembro de 1996. Lei de Diretrizes e Bases da Educação Nacional. Brasília, DF: 20 de dezembro de 1996.

Brasil. Secretaria de Educação Fundamental. Parâmetros curriculares nacionais: introdução aos parâmetros curriculares nacionais / Secretaria de Educação Fundamental. - Brasília: MEC/SEF, 1997. 126p

BOOTH, Tony; AINSCOW, Mel. Index para Inclusão: desenvolvendo a aprendizagem e a participação na escola. 3. ed. UNESCO/CSIE. Rio de Janeiro, 2011. 
Tradução de Mônica Pereira dos Santos. Disponível em: <https://www. lapeadeufrj.rio.br/materiais-e-dicas/index-para-a-inclus $\% \mathrm{C} 3 \% \mathrm{~A} 3 \mathrm{o}>$. Acesso em: 16 abr. 2021.

BRASIL. Resolução CNE/CP 1/2006. Diário Oficial da União, Brasília, 16 de maio de 2006, Seção 1, p. 11.

BRASIL. Lei no 13.146, de 06 de julho de 2015. Institui a Lei Brasileira de Inclusão da Pessoa com Deficiência (Estatuto da Pessoa com Deficiência). Disponível em: http://www.planalto.gov.br/ccivil_03/_ato2015-2018/2015/lei/113146.htm. Acesso em 18/04/2021.

BRASIL. DECLARAÇÃO UNIVERSAL DOS DIREITOS HUMANOS. Assembleia Geral das Nações Unidas em Paris. 10 dez. 1948.

BRASIL, Ministério da Educação. Plano de Desenvolvimento da Educação (PDE): Prova Brasil: ensino fundamental: matrizes de referências, tópicos e descritores. Brasília: MEC, SEB, INEP, 2008.

BRUNO, Marilda Moraes Garcia. Educação infantil: saberes e práticas da inclusão: introdução. [4. ed.] / elaboração Marilda Moraes Garcia Bruno. Brasília : MEC, Secretaria de Educação Especial, 2006. 45 p.

INFANTE, ISABEL. El dominio del código escrito o los niveles de alfabetismo: alguns resultados de um estudio en siete países de América Latina. In: INFANTE, Isabel (org). Analfabetismo funcional. Revista Contemporaneidade e Educação. Instituto de Estudos da Cultura e Educação Continuada (IEC). Rio de Janeiro, Ano IV, no 05, 1999 - p.07

KULLMANN, Niuana; LEMONS, Caroline Caldas. O papel do professor na libertação dos educandos. UCS - Universidade de Caxias do Sul - RS - Brasil, PAINEL TEMÁTICO 03, Perspectivas freireanas para Educação. E-book do I SIBFORP \& II JIPPGE - BR/A. 27 a 30 de agosto de 2018.

MARCONI, Marina de Andrade; LAKATOS, Eva Maria. Fundamentos de Metodologia Científica. 5. ed. - São Paulo: Atlas 2003. 
MARTÍNEZ, María Elena e SEOANE, Viviana Isabel. Disputas por el derecho a la educación y la educación pública en América Latina: políticas, instituciones y sujetos en la gubernamentalidad neoliberal. Revista Brasileira de Política e Administração da Educação - RBPAE - v. 36, n. 1, p. 009 - 014, jan./ abr. 2020.

MELO, Sandra Cordeiro de; MASCARENHAS, Jéssica Cristina. Autismo e Educação: uma revisão da literatura recente sobre experiências de inclusão. No prelo.

MORTATTI, Maria do Rosário Longo. Alfabetização no Brasil: conjecturas sobre as relações entre políticas públicas e seus sujeitos privados. Revista Brasileira de Educação v. 15 n. 44 maio/ago 2010.

MORTATTI, Maria do Rosário Longo. Educação e letramento. São Paulo: UNESP, 2004.

MOURA, Eliel da Silva; NAJJAR, Jorge; CARNEIRO, Waldeck. Neoliberalização e reforma educacional: a chegada da organização Teach for America no Brasil. Revista Brasileira de Política e Administração da Educação - RBPAE - v. 35, n. 2, p. 447 - 468, mai./ago. 2019. p.447.

PAIVA, Vanilda. Educação popular e educação de adultos. São Paulo: Edições Loyola, 1987.

SANTOS, Mônica Pereira dos. Dialogando sobre inclusão em educação: contando casos (e descasos). Curitiba: CRV, 2013.

SILVA, Tatiany Michelle Gonçalves da. ALMEIDA JUNIOR, Dirceu Manoel de. DIAS, Rodrigo Francisco. Como preparar um professor para "ser" inclusivo: reflexões sobre a formação docente. Research, Society and Development, v. 9, n. 102020.

TAYASSU, Catitu. Alfabetização e letramento: condições de inclusão social. In: GONÇALVES, Adair Vieira; PINHEIRO, Alexandra Santos. Nas trilhas do letramento: entre teoria, prática e formação docente. Campinas, SP: Mercado de Letras; Dourados, MS: Editora da Universidade Federal de Grande Dourados, 2011. 
UNESCO. Educação para todos: o compromisso de Dakar. Dakar, Senegal: UNESCO, 2000.

UNESCO. Declaração mundial sobre educação para todos e plano de ação para satisfazer as necessidades básicas de aprendizagem. Jomtien, Tailândia: UNESCO,1990.

UNESCO. Marco da educação 2030: Declaração de Incheon. Incheon, Coréia do Sul, 2015.

UNESCO. Organização das Nações Unidas para a Educação, Ciência e Cultura. Relatório de Monitoramento Global da Educação. UNESCO, 2016. Disponível em: https://goo.gl/J1a7LO. Acesso em: 16 abr. 2021.

\section{Elaine Constant}

Possui graduação em Psicologia pela Faculdade de Humanidades Pedro II, Mestrado em Educação pela Universidade do Estado do Rio de Janeiro e Doutorado em Políticas Públicas e Formação Humana pela Universidade do Estado do Rio de Janeiro. Tem experiência na área de Políticas Públicas da Educação, avaliação do processo de ensino aprendizagem, currículo escolar e formação docente.

Atualmente é Professora Associada da Universidade Federal do Rio de Janeiro (UFRJ). Coordena o Laboratório Integrado de estudos de Alfabetização e Linguagem (LIA). Coordenou a Formação do Pacto Nacional pela Alfabetização na Idade Certa (PNAIC) no estado do Rio de Janeiro. Professora da PósGraduação em Políticas Públicas em Direitos Humanos (PPDH) do Núcleo de Estudos de Políticas Públicas em Direitos Humanos (NEPP-DH) da UFRJ, em especial, lecionando nas disciplinas de Educação em Direitos Humanos, Políticas Públicas da Educação e Desigualdade Social. E-mail: constant.ela@gmail.com

\section{Sandra Cordeiro de Mel}

É graduada em psicologia pela Universidade Católica de Petrópolis (1998), Mestre em Educação pela Universidade do Estado do Rio de Janeiro (2004), Doutora em Educação pela Universidade Federal do Rio de Janeiro (2010) e Pós-Doutora em Educação pela Universidade do Estado do Rio de Janeiro. É Professora Associada, atua no Programa de Pós-Graduação em Educação PPGE, e na graduação da Faculdade de Educação da Universidade Federal do Rio de Janeiro. É Coordenadora do Laboratório de Inclusão, Mediação Simbólica, Desenvolvimento e Aprendizagem - LIMDA da Faculdade de Educação da UFRJ. Desenvolve pesquisas sobre Inclusão em Educação, Desenvolvimento, Aprendizagem, Transtorno do Espectro Autista e Síndrome de Down. E-mail: sandracmello@gmail.com 


\section{Daiane França}

Graduação em Licenciatura em Pedagogia pela Universidade Federal do Estado do Rio de Janeiro (UNIRIO) Pós Graduada em Psicopedagogia Clínica e Institucional pela Universidade Cândido Mendes (UCAM). Atualmente é professora da rede Faetec do Rio de Janeiro. E-mail: franca.daiane@gmail.com E-mail: franca.daiane@gmail.com 